\title{
Atrial fibrillation in the Indigenous populations of Australia, Canada, New Zealand, and the United States: a systematic scoping review
}

\author{
Judith M. Katzenellenbogen ${ }^{1,2 \dagger}$, John A. Woods ${ }^{1{ }^{*}}$, Tiew-Hwa Katherine Teng ${ }^{1}$ and Sandra C. Thompson ${ }^{1}$
}

\begin{abstract}
Background: The epidemiology of atrial fibrillation (AF) among Indigenous minorities in affluent countries is poorly delineated, despite the high cardiovascular disease burden in these populations. We undertook a systematic scoping review examining the epidemiology of AF in the Indigenous populations of Australia, Canada, New Zealand (NZ) and the United States (US).

Methods: PubMed, Scopus, EMBASE and CINAHL-Plus databases were systematically searched in May 2014. Supplementary full-text searches of Google Scholar and government website searches were also undertaken.

Results: Key findings from 27 publications with diverse aims and methods were included. Small studies from Canada and NZ suggest higher AF prevalence in Indigenous than other populations. However, this was not reflected in a large sample of US male military veterans. No data were identified on community-based incidence rates of AF in Indigenous populations. Australian and Canadian studies indicate higher first-ever and overall AF hospitalisation rates among Indigenous than other populations, at younger ages and with more comorbidity. Studies in stroke, heart failure and other clinical groups demonstrate AF as a common comorbidity, with AF possibly more prevalent at younger ages in Indigenous people. Indigenous patients have similar early post-hospitalisation adjusted mortality but higher 1-year risk-adjusted mortality than non-Indigenous patients.

Conclusions: No clear epidemiological pattern of AF frequency across the considered Indigenous populations emerges from the limited available evidence. AF should be included in key conditions reported in national surveillance reports, although Indigenous identifiers are required in administrative data from Canada and the US. Sufficiently powered, community-based studies of AF epidemiology in diverse Indigenous populations are needed.
\end{abstract}

\section{Background}

Indigenous peoples living in affluent countries have poor health profiles and considerably diminished life expectancies compared with their non-Indigenous counterparts [1-3]. Although the Indigenous populations of Australia, Canada, New Zealand (NZ) and the United States (US) are highly diverse [4], they

\footnotetext{
* Correspondence: john.woods@uwa.edu.au

${ }^{\dagger}$ Equal contributors

'Western Australian Centre for Rural Health, The University of Western Australia (M706), 35 Stirling Highway, Crawley, Western Australia 6009, Australia

Full list of author information is available at the end of the article
}

'share similar historical experiences, socioeconomic disadvantage, and health status' [5]. As such, these four populations 'are often seen as natural comparators in terms of Indigenous wellbeing' [6] in health research literature [7-9] and elsewhere [10]. An excess burden of cardiovascular diseases (CVD), typically presenting at a younger age, predominates the gap in their health outcomes $[11,12]$.

Atrial fibrillation (AF), the most common sustained cardiac arrhythmia, is increasing in prevalence and incidence globally [13-15]. Prevalence increases progressively with age, and is higher among men than women [16]. AF causes serious complications, notably heart

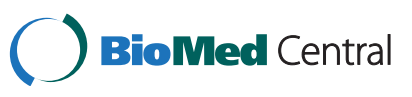


failure and thromboembolic sequelae such as stroke [17-19], with stroke prevention a cornerstone of management [20]. AF is associated with a substantial increase in overall mortality [21], although the direct causality of this association remains contentious [22].

AF characteristically accompanies the spectrum of common CVDs disproportionately afflicting Indigenous populations $[11,23]$, so this arrhythmia could be predicted to affect them with increased frequency. However, many large studies and recent international reviews of AF epidemiology notably lack data on Indigenous populations $[13-15,24]$. This omission may be related to the low proportion of Indigenous people in most jurisdictions, and to inadequate documentation of Indigenous identity in administrative data. This paper reports a scoping review mapping the current knowledge of AF epidemiology in the Indigenous populations of Australia, Canada, NZ and the US.

\section{Methods}

Information sources and search strategy

Indigenous populations considered were those of Australia (Aboriginal and Torres Strait Islander peoples), NZ (Māori), Canada (Aboriginal peoples comprising First Nations, Métis, and Inuit), and the US (Native American, Native Alaskan, and Native Hawaiian).

The multifaceted search strategy incorporated both journal publications and 'grey' literature (including conference abstracts). An electronic database search incorporating PubMed, Scopus, EMBASE and CINAHL-Plus was conducted in January 2014 and updated in May 2014. Records retrieved were those containing terms related to both Indigenous populations and atrial fibrillation (Additional file 1: Table S1), with an equivalent search conducted in each database. To maximise identification of peer-reviewed papers, the standard multidatabase search was supplemented by a series of full-text journal article searches using Google Scholar. In view of the limited Boolean searching functionality of Google, a series of complementary simple searches was done to maximise identification of pertinent references. In these searches $(23 / 05 / 2014)$, using the 'Sort by relevance' function, the phrase-forced term "atrial fibrillation" was searched separately in combination with each of the following terms: aboriginal, maori, "native american", "first nations", metis, inuit and indigenous. The fulltext of the first 50 references retrieved (or all references if $<50$ were retrieved) in each of these searches was reviewed, except that in the final search ("indigenous" and "atrial fibrillation"), the first 100 references were reviewed. A second series of Google scholar searches date-restricted to 2014 was also done (27/05/2014), to maximise retrieval of recent publications that may have been missed in the systematic multi-database search.

The grey literature was searched using Google as well as applicable government departmental websites from each country. Additionally, advice was sought on data sources that may have been overlooked, by means of direct email contact with relevant experts in NZ and Canada, in order to complement the authors' pre-existing knowledge of Australian administrative health data collections.

The systematic searches were supplemented by citation screening of retrieved records and the addition of publications otherwise known to the authors.

\section{Study selection and inclusion criteria}

Records retrieved from the searches were catalogued in EndNote ${ }^{\circ}$. Duplicates were removed by automation supplemented with manual checking.

Publications considered for inclusion were those containing original epidemiologic or health services data on AF in the designated Indigenous populations. 'Epidemiological data' was broadly defined to include metrics such as incidence, prevalence, aetiology, risk factors and health outcomes (including mortality). Inclusion was date-restricted to articles published from 1980 onwards. There was no formal restriction by language of publication. However, all pertinent records identified had been published in English or bilingually.

Full-length articles as well as abstracts (where no full length published article was identified) were eligible for inclusion. One reviewer (JAW) excluded studies judged on the basis of title and abstract to be clearly non-relevant according to pre-defined criteria (pre-1980; wrong country; case report; non-anthropological meaning of 'indigenous' such as indigenous botanical). Two reviewers (JMK and JAW) each screened the remaining titles and abstracts for relevance. Disagreements were resolved by consensus. Articles were excluded if Indigenous data were only included as baseline characteristics or had been combined with other minority ethnic groups, or if there were few $(<10)$ Indigenous AF cases.

\section{Data extraction}

Article details were extracted independently by reviewers (JMK, T-HT, JAW) onto a predesigned spreadsheet template. Studies were grouped according to the type(s) of epidemiological data on AF presented. The validity of study hypotheses on epidemiological indices of Indigenous AF was assessed in applicable cases using the NewcastleOttawa Scale (NOS), which awards up to 9 or 10 stars for quality, based upon assessment of sample selection and comparability, and exposure/outcome ascertainment [25]. Papers were categorised by type of epidemiological data provided. 


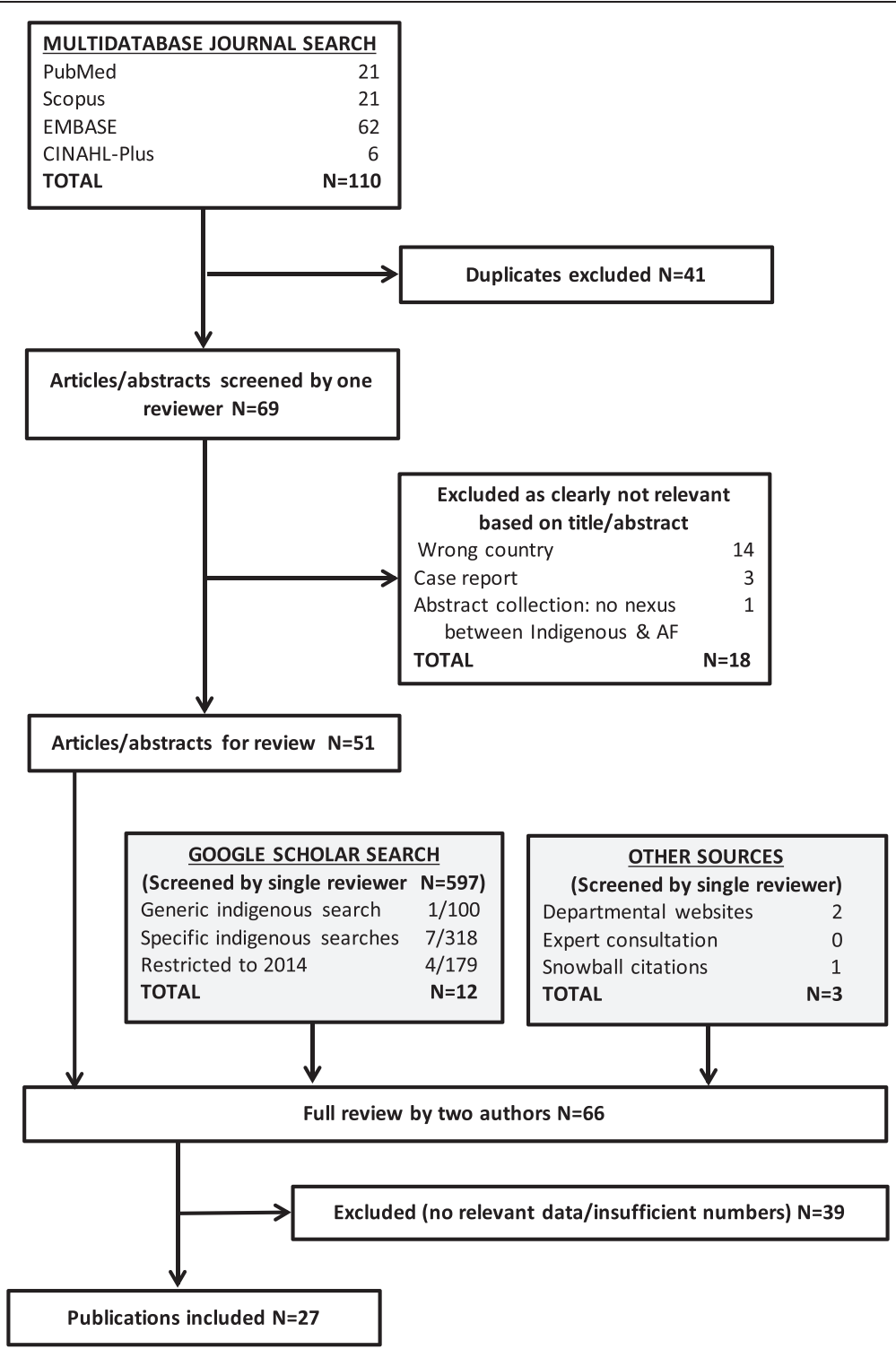

Fig. 1 Flowchart of search strategy and output

\section{Results}

Of 69 unique publications identified, 51 went to full review, of which 27 met the inclusion criteria (Fig. 1). The US and Australia contributed the majority, with descriptions of $\mathrm{AF}$ in clinical groups $(50 \%)$ and recent publications (2006 onwards) dominating (Table 1). In the majority of papers identified, either AF was incidental to the study rather than a core or major focus, or Indigenous data were incidental or uninterpretable due to insufficient subject numbers. In the interval between the database searches and manuscript completion, data from two of the identified abstracts [26, 27] and one report [28] were published as peer-reviewed journal articles and were updated as such in the review [29-31].

\section{Antecedents of AF}

No studies were identified with data on the independent relationship of AF to antecedent lifestyle risk factors or medical conditions among Indigenous populations, or on Indigenous versus non-Indigenous differentials in this regard. The Strong Heart Study [11], a large US cohort restricted to Native American subjects followed up for 10 years, produced two abstracts investigating novel AF antecedents in this population (Table 2). Independent risk factors for new-onset $\mathrm{AF}$ were increasing age $(\mathrm{HR}=1.08)$, male sex $(\mathrm{HR}=1.67), \mathrm{C}$-reactive protein $(\mathrm{HR}=1.44)$ [32], serum fibrinogen $(\mathrm{HR}=1.31)$ [32], Left Ventricular Mass Index $(\mathrm{HR}=1.31)$ [33], and Left ventricular ejection fraction $(\mathrm{HR}=0.73)$ [33]. 
Table 1 Characteristics of publications retrieved_classified by country

\begin{tabular}{|c|c|c|c|c|c|}
\hline & Australia & New Zealand & USA & Canada & Total \\
\hline \multicolumn{6}{|l|}{ Publication type } \\
\hline Journal article & 8 & 2 & 7 & 3 & 20 \\
\hline Conference abstract & 0 & 3 & 2 & 0 & 5 \\
\hline Report & 1 & 1 & 0 & 0 & 2 \\
\hline \multicolumn{6}{|l|}{ Study design } \\
\hline Cohort & 1 & 1 & 2 & 1 & 5 \\
\hline Case-control & 0 & 0 & 0 & 0 & 0 \\
\hline Cross-sectional & 4 & 0 & 5 & 0 & 9 \\
\hline Descriptive & 4 & 5 & 2 & 2 & 13 \\
\hline \multicolumn{6}{|l|}{ Epidemiological index or theme ${ }^{a}$} \\
\hline Antecedents of AF & 0 & 0 & 2 & 0 & 2 \\
\hline Incidence of AF in a population & 1 & 0 & 0 & 1 & 2 \\
\hline Prevalence of AF in a population & 1 & 2 & 1 & 1 & 5 \\
\hline AF in primary care consultations & 1 & 0 & 0 & 0 & 1 \\
\hline AF hospital admission rates & 0 & 1 & 0 & 0 & 1 \\
\hline Outcomes in AF patients & 1 & 1 & 1 & 1 & 4 \\
\hline Health service provision & 0 & 0 & 0 & 1 & 1 \\
\hline AF as an outcome & 0 & 0 & 1 & 0 & 1 \\
\hline Occurrence of AF in a clinical group & 6 & 2 & 4 & 2 & 14 \\
\hline \multicolumn{6}{|l|}{ Primary focus on AF } \\
\hline Yes_-Indigenous AF & 3 & 2 & 3 & 1 & 9 \\
\hline Yes-AF (Other) & 0 & 1 & 3 & 0 & 4 \\
\hline No & 6 & 3 & 3 & 2 & 14 \\
\hline \multicolumn{6}{|l|}{ Setting } \\
\hline Community & 1 & 2 & 4 & 0 & 7 \\
\hline Primary care & 1 & 0 & 0 & 0 & 1 \\
\hline Hospital patients: no population denominator & 4 & 3 & 4 & 1 & 12 \\
\hline Hospital patients: population denominator & 3 & 1 & 0 & 2 & 6 \\
\hline Hospital patients and community & 0 & 0 & 1 & 0 & 1 \\
\hline \multicolumn{6}{|l|}{ Calendar period of final data collection } \\
\hline 1980-1995 & 0 & 1 & 0 & 0 & 1 \\
\hline 1996-2005 & 0 & 2 & 3 & 0 & 5 \\
\hline 2006 onwards & 9 & 3 & 6 & 3 & 21 \\
\hline Total & 9 & 6 & 10 & 3 & 27 \\
\hline
\end{tabular}

${ }^{\mathrm{a}}$ Studies may be included in more than one category

\section{Population-based epidemiological indices of AF Incidence}

Two studies provided data on population-based AF hospitalised incidence among Indigenous peoples (Table 2). A Canadian study provided cohort data from the Ontario Métis Register linked with emergency department and hospital inpatient records. The age- and sex-adjusted incidence of AF per 100 persons (aged 20105) was 0.62 (95\% confidence interval [CI] 0.50-0.73) in the Métis versus 0.32 (CI 0.32-0.32) in the general Ontario population $(p<0.001)$ [31]. Individuals identified in the register constituted only $18 \%$ of Ontarian Métis, and may not have been representative of the provincial Métis population. Additionally, the number of incident AF cases was very small $(n=56)$. A Western Australian (WA) study using linked inpatient and mortality records provided estimates for different age and sex groups, highlighting the greater disparities in 
Table 2 Studies of antecedents and population-based occurrence of atrial fibrillation

\begin{tabular}{lll}
\hline Author (Year) & Country & Key findings on Indigenous AF \\
Publication type & Indigenous population & Quality score (Newcastle-Ottawa \\
& Calendar period & Scale applied only to Indigenous \\
& & AF data) \\
& Comments
\end{tabular}

\section{Antecedents of AF}

Title: Association of Markers of Inflammation with New-Onset Atrial Fibrillation in a Population-Based Sample: The Strong Heart Study

Design: Population-based cohort study New-onset AF ( $n=100$ participants) NOS: N/A (abstract) No non-American independently predicted by serum - Indian comparis CRP level (HR 1.44 per mg/L Indian comparison group; data [95 \% C 1.17-1.77], $P=0.001$, and that CRP \& fibrinogalisable evidence by fibrinogen level (HR 1.31 per risk factors for new-onset AF $83.44 \mathrm{mg} / \mathrm{dL}[=1 \mathrm{SD}$ of mean] (independent of effects of gender, [95\% Cl 1.06-1.61], $p=0.013$ ) age, hypertension, BMl, and urinary

Population: American Indians

Period: enrolled 1993-1995 with 10 years follow-up

Sample size: 3541
Data Source: Strong Heart

Study: prospectively collected

population-based survey of risk factors

Setting: 13 American Indian

communities

Sample size: 354

Title: Association of Left Ventricular Mass and Ejection Fraction with New-Onset Atrial Fibrillation in a Population-Based Sample: The Strong Heart Study

Zacks (2006) [33] Conference abstract Country: US

Population: American Indians

Period: enrolled 1993-1995 with

10 years follow-up

Sample size: 3541
Design: Population-based cohort study

\section{inde} increased LV mass indexed for heigh
(HR 1.49 per $11 \mathrm{gm} / \mathrm{m}^{2.7}[=1 \mathrm{SD}$ of mean][95 \% Cl 1.24-1.78], $\mathrm{p} \leq 0.000$ and $(n=88)$ by reduced LVEF (HR 0.65 per $14 \%$ [ $=1$ SD of mean] [95\% Cl 0.52-0.82], p $\leq 0.0001$ )

Data Source: Strong Heart

Study: prospectively collected population-based survey of risk factors

Setting: 13 American Indian

communities

Sample size: 3541

Incidence in population

Title: Cardiovascular Disease Rates, Outcomes, and Quality of Care in Ontario Métis: A Population-Based Cohort Study
Atzema (2015) [31] Journal article
Country: Canada (Ontario only)
Design: Retrospective cohort study

(this study has multiple outcomes)

(18\% of Métis population)

Age- \& sex-adjusted incidence per 100 (Cl): Métis0.62 (0.50-0.73)

NOS (cohort): $7 / 9$ Incidence

well-defined. Register not representative, Out-of-hospital cases not included; very small numbers of incident cases
NOS: N/A (abstract) No non-American Indian comparison group; data mass generalisable evidence mass index and LVEF are (indive risk factors for new-onset A age, hypertension, BMI, urinary albumin-creatinine ratio, CRP and fibrinogen) 
Table 2 Studies of antecedents and population-based occurrence of atrial fibrillation (Continued)

\begin{tabular}{|c|c|c|c|c|}
\hline & Population: Métis & $\begin{array}{l}\text { Data Source: Ontario Métis register } \\
\text { linked to emergency department (ED), } \\
\text { in-patient hospital \& mortality records }\end{array}$ & All Ontario $0.32(0.32-0.32)$ & \\
\hline & Period: 2006-2011 & Setting: ED and hospital based cases & $p<0.001$ & \\
\hline & Age: 20 years \& over & Other: 5-year clearance period & & \\
\hline & & $\begin{array}{l}\text { Sample size: } 56 \text { cases of } 12,550 \\
\text { ( } 7 \% \text { of provincial Métis population) }\end{array}$ & & \\
\hline \multicolumn{5}{|c|}{ Title: Initial hospitalisation for atrial fibrillation in Aboriginal and non-Aboriginal populations in Western Australia } \\
\hline \multirow[t]{5}{*}{$\begin{array}{l}\text { Katzenellenbogen (2015) [30] } \\
\text { Conference abstract later published } \\
\text { as a journal article (this study has } \\
\text { multiple outcomes) }\end{array}$} & $\begin{array}{l}\text { Country: Australia } \\
\text { (Western Australia only) }\end{array}$ & $\begin{array}{l}\text { Design: baseline data of retrospective } \\
\text { cohort }\end{array}$ & $\begin{array}{l}\text { Aboriginal age-specific rates higher } \\
\text { than non-Aboriginal rates in all } \\
\text { ages }<70 \text { years }\end{array}$ & $\begin{array}{l}\text { NOS (adapted for cross-sectional): 10/10 } \\
\text { Coverage of whole State with linked } \\
\text { data but admitted hospital cases only; } \\
\text { no data on diagnostic tests and } \\
\text { medications; diagnostic codes } \\
\text { not validated }\end{array}$ \\
\hline & Population: Aboriginal & $\begin{array}{l}\text { Data Source: Linked hospital and } \\
\text { death records }\end{array}$ & $\begin{array}{l}\text { ASRR: } 20-54 \text { years }=3.6 \text { (males) } \\
\text { and } 6.4 \text { (females) } 55-84 \text { years }=1.3 \\
\text { (males) and } 1.8 \text { (females) }\end{array}$ & \\
\hline & Age: $20-84$ years & $\begin{array}{l}\text { Setting: Western Australian hospital } \\
\text { cases }\end{array}$ & & \\
\hline & Period: 2000-09 & Other: 15-year clearance period & & \\
\hline & & $\begin{array}{l}\text { Sample size: } 37,097 \text { AF cases, } \\
923 \text { Aboriginal }\end{array}$ & & \\
\hline \multicolumn{5}{|l|}{ Prevalence in population } \\
\hline \multicolumn{5}{|c|}{ Title: Cardiovascular Disease Rates, Outcomes, and Quality of Care in Ontario Métis: A Population-Based Cohort Study } \\
\hline \multirow[t]{4}{*}{$\begin{array}{l}\text { Atzema (2015) [31] Journal article } \\
\text { (this study has multiple outcomes) }\end{array}$} & Country: Canada (Ontario only) & Design: Retrospective study & $\begin{array}{l}\text { Age- \& sex-adjusted prevalence } \\
\text { per } 100 \text { (CI): Métis } 2.08 \text { (1.82-2.34) }\end{array}$ & $\begin{array}{l}\text { NOS (adapted for cross-sectional): } \\
\text { 8/10Prevalence not well-defined. } \\
\text { Register not representative, } \\
\text { out-of-hospital cases not included, } \\
\text { numerators not provided and likely } \\
\text { to be small numbers }\end{array}$ \\
\hline & Population: Métis & $\begin{array}{l}\text { Data Source: Métis register linked to } \\
\text { emergency department (ED), } \\
\text { in-patient hospital \& mortality records }\end{array}$ & All Ontario $1.42(1.41-1.43)$ & \\
\hline & Period: 2006-2011 & Setting: ED and hospital based cases & $p<0.001$ & \\
\hline & Age: 20 years \& over & $\begin{array}{l}\text { Sample size: } 12,550 \text { ( } 17 \% \text { of provincial } \\
\text { Métis population) }\end{array}$ & & \\
\hline
\end{tabular}


Table 2 Studies of antecedents and population-based occurrence of atrial fibrillation (Continued)

Title: Racial differences in the prevalence of atrial fibrillation among males
Borzecki (2008) [34] Journal article
Country: US
Design: Cross-sectional

Population: Native American/
Alaskan/Hawaiian

Period: 1997-1999

Age: 18 years \& over
Data Source: administrative database

plus health survey

Setting: population-based (male

veterans)

Sample size: 664,754 respondents

(27,697 Native Americans)

Titles: 1. Heart failure, ventricular dysfunction and risk factor prevalence in Australian Aboriginal peoples: the Heart of the Heart Study

2. Cardiometabolic risk and disease in Indigenous Australians: the Heart of the Heart Study

McGrady (2012) [36] Brown (2014) [35] C Country: Australia

Design: Cross-sectional

Journal articles

Population: Aboriginal

Age: $17+$ years

Period: 2008-09

Title: Twelve Lead Electrocardiographic Findings Among Māori and non-Māori at Risk of Cardiovascular Disease in NZ

Martin (2013) [37] Conference Country: NZ
abstract

Population: Māori

Data Source: 'randomly selected'
Data Source: Community survey, including psycho-social, biological and clinical measures

Setting: 3 communities in Central

Australia

Sample size: 436 volunteers

Design: baseline descriptive (within cohort study)

Atrial fibrillation frequencies: $2 \%$ rural Māori $1.2 \%$ urban Māori $0.4 \%$ urban non-Māori
Prevalence in male Veterans higher NOS: (adapted for cross-sectional) among White than Native Americans 10/10 High quality whole-of-nation Age-adjusted: White $5.7 \%$ Native American $5.4 \%$ Multivariate OR 1.15; $95 \%$ Cl 1.04-1.27 (adjusted for age, BMl and predisposing comorbidities)

Crude prevalence of $\mathrm{AF}=2.5 \%$ Similar prevalence $<40$ and $40-55$ years $(1 \% ; n=3)$, higher prevalence $56+$ years $(8 \%$; $n=8)$. remote and town communities.

NOS (adapted for cross sectional): 8/10 (AF not main outcome) Standardised measurements; out-of-hospital and undiagnosed cases included; small numbers; estimated $10 \%$ enrolled, representativeness unknown, possible selection bias

NOS: N/A (abstract) No data provided on age/sex distribution, no statistical inference community samples from the Hauora Manawa Community Heart Study cohort: 12-lead ECG 
Table 2 Studies of antecedents and population-based occurrence of atrial fibrillation (Continued)

$\begin{array}{ll}\text { Age: 20-64 years } & \text { Setting: two Māori Communities } \\ & \text { (rural, urban) and a non-Māori urban } \\ & \text { cohort }\end{array}$

Period: Not known Sample size: 252 rural Māori, 243 urban

Māori, 256 urban non- Mãori

Title: The Burden of Atrial Fibrillation in Octogenarians

Teh (2013) [38] Conference abstract Country: NZ

Population: Māori

Age: $80-90$

Period: 2010-2011
Design: baseline descriptive (within cohort study)

Data Source: Life and Living to Advanced Age (NZ) cohort: 12-lead

ECG plus NZHIS

Setting: community

Sample size: Overall cohort: 421 Māori aged 80-90; 516 non- Mãori all aged 85.615 (66 \%) participants had ECG;

870 (93\%) consented to NZHIS record examination
30 \% Māori versus 21 \% non-Māor had AF, either on ECG or NZHIS records $7 \%$ Māori versus $4 \%$ non-Māori had AF newly detected by study ECG
NOS: N/A (abstract) No statistical inferential data or eligibility exclusions reported Stroke reported as a comorbidity in 27 \% of Mãori and $35 \%$ of non-Māori subjects

Admission Rates (unlinked)

Title: The Management of People with Atrial Fibrillation and Flutter: Evidence-based Best Practice Guideline

New Zealand Guidelines Group (2005) C Country: NZ [39] Report
Design: Descriptive

Population: Māori

Period: 2001-2002

Age: unrestricted
Hospital discharges with AF diagnosis: Age-standardised rate for Mãori almost twice that of for Māori almost twice that of
non-Māori (104 per 100,000 vs non-Māori (104 per 100,000 vs
57 per 100,000, $p<0.05)$ Standardised 57 per 100,000, $p<0.05$ ) Standard
discharge ratio (observed versus expected) 1.945 for Māori \& 0.972 for 'others' (where 1.0 is the national average) Modal age group: Māori 65-69 years, 'other' males 75-79 years, 'other' females $>85$ years
NOS: N/A (report with insufficient methodological detail published) Unlinked administrative data

.

Data Source: National minimum

dataset

Setting: Hospital patients

Sample size: (whole of NZ data;

sample size not stated) 
younger adults [30]. At all age groups under 65 years, Aboriginal rates were significantly higher than nonAboriginal rates. Among adults aged 20-54 years, the age-standardised rate ratios (ASRRs) for incident (hospitalised) AF were 3.6 in males and 6.4 in females; in the 55-84 year age group, ASRRs were 1.3 and 1.8 respectively. AF was more likely in Aboriginal than among nonAboriginal people to be an emergency admission and a diagnosis secondary to another principal diagnosis (mainly other CVD). Additionally, case complexity as reflected in co-morbidity profile was greater in Aboriginal patients. Both publications relied on hospital data only, thus not capturing incident cases in the community.

\section{Prevalence}

Among the studies that investigated AF prevalence in Indigenous versus other racial groups (Table 2), only one (from the US) provided whole-of-nation comparative data [34]. In this large study (total subjects $n=664,754$; Native American $n=27,697$ ), based on data linked between two national Veterans Health Administration administrative databases and a mailed questionnaire survey, the age-adjusted prevalence of AF was similar among White (5.7 \%) and Native American (5.4 \%) males. Subjects included in these estimates were those who responded to the survey (response $67 \%$ Whites, $55 \%$ Native Americans). After multivariate adjustment for age, body-mass index (BMI) and predisposing comorbidities, AF was less prevalent among Native American than White adult males (adjusted odds ratio White versus Native Americans: 1.15; CI 1.04-1.27).

The Ontario Métis Register provided data derived from emergency department (ED) and hospital databases on AF prevalence among Ontarians [31]. The reported age- and sex-adjusted prevalence of AF in subjects 20 years and over was 2.08 (CI 1.82-2.34) per 100 persons in the Métis, versus 1.42 (CI 1.41-1.43) in the general Ontarian population $(p<0.001)$. However, these data are difficult to interpret as the basis for measuring prevalence was not clearly defined, and information on out-of-hospital cases was lacking.

Two peer-reviewed journal papers based on the Heart of the Heart Study $[35,36]$ reported data on AF prevalence in three central Australian Indigenous communities, providing no comparative data. This cross-sectional study was designed to investigate the burden and correlates of cardiovascular and other diseases in a representative sample of community dwelling adults. The study incorporated detailed clinical and diagnostic cardiovascular assessment of 436 volunteer subjects. The crude reported prevalence of AF was $2.5 \%$; this predictably rose with age. Caveats on the interpretation of these estimates include the small number of subjects and the unknown representativeness of the sample in relation to the communities.

Prevalence data of AF from separate cohort studies among Indigenous (Māori) communities from NZ were reported in two conference abstracts. Firstly, in data from the Hauora Manawa Project, randomly selected community-based samples, each comprising about 250 individuals from two Māori Communities (one rural and one urban), were compared with an urban non-Māori community [37]. The reported crude AF prevalence was higher in both Māori communities (2 \% and $1.2 \%$ respectively) than among the non-Mãori subjects (0.4\%). The other abstract reported AF frequency among 937 octagenarian subjects (421 Māori, 516 non- Mãori) [38]. $\mathrm{AF}$ was more common among Māori (30 \%) than nonMāori participants (21 \%).

\section{Life-time risk}

No publications provided data on life-time risk of AF among the Indigenous populations of the selected countries.

\section{Hospital admission rates}

No peer-reviewed publications were identified with population-based data on AF-related overall hospital admission frequency according to Indigenous status. The only whole-jurisdictional administrative data on Indigenous AF admissions were those reported from the NZ National Minimum Dataset where the agestandardised rate of hospital discharges in 2001-02 among Māori was almost twice that among non-Māori (104 per 100,000 vs 57 per $100,000, p<0.05$ ) [39]. These data were unlinked, precluding person-level analysis of admission patterns. Publications from the Australian Institute of Health and Welfare report unlinked data on hospitalisations for CVD and do not distinguish AF from other cardiac conditions in relation to Indigenous hospitalisations [40].

\section{Outcomes in AF patients}

Three publications, two from North America and one from Australia, provided data on outcomes among Indigenous patients hospitalised with AF (Table 3). In the study on CVDs among the Métis Nation of Ontario, age- and sex-standardised all-cause mortality $(n=6$ Métis deaths) at one year following incident AF admission or emergency presentation was 2.1 times higher among Métis than the general Ontarian population $(p=0.06$; borderline significance). There was no significant difference in disease-specific hospitalisations in the first year after incident diagnosis (rates age- and sex-standardised to those of general Ontarian population 1.23 (CI $0.73-2.08, p=0.44$ ) [31]. A US study based on the 2008 Nationwide Inpatient Sample, which 
Table 3 Studies of atrial fibrillation outcomes

\begin{tabular}{lll}
\hline Author (Year) & Country & Key findings on Indigenous AF \\
Publication type & $\begin{array}{l}\text { Indigenous population } \\
\text { Calendar period }\end{array}$ & Quality score (Newcastle-Ottawa Scale \\
& Age range & applied only to Indigenous \\
AF data) & Comments \\
\hline
\end{tabular}

Outcomes in AF patients

Title: Cardiovascular Disease Rates, Outcomes, and Quality of Care in Ontario Métis: A Population-Based Cohort Study

Atzema (2015) [31] Journal article Country: Canada (Ontario only) Design: Retrospective cohort study

(this study has multiple outcomes)

Population: Métis

Period: $2006-2011$

Age: $20+$ years
Outcomes: One-year all-cause and cardiovascular mortality in incident cases ()

Sample size: 6 deaths in 56 Métis; 32,387 general Ontarian incident cases
Age- \& sex-adjusted all cause mortality (Cl) Métis 16.6 (7.3-25.4) All Ontario 7.8 (75-8.1) $p=0.06$

NOS (cohort): 7/9 'Incidence case' denominator determined by first emergency department presentation or hospitalisation onlySmall number of Métis subjects

Age- \& sex-adjusted cardiovascular mortality (Cl) Métis 10.0 (2.4-17.7)

All Ontario 4.8 (4.6-5.0) $p=0.19$

Title: African Americans have the highest risk of in-hospital mortality with atrial fibrillation related hospitalizations among all racial/ethnic groups: A nationwide analysis

Turagam (2012) [41] Journal Country: US research letter
Design: cross-sectional/cohort

Data Source: Nationwide Inpatient Sample hospitalization database

Period: 2008

Age: uncertain

Setting: hospitals
Sample size: 425470 admitted with AF

as principal diagnosis

Title: Initial hospitalisation for atrial fibrillation in Aboriginal and non-Aboriginal populations in Western Australia

$\begin{array}{ll}\text { Katzenellenbogen (2015) [30] } & \text { Country: Australia } \\ \text { Conference abstract later } & \text { (Western Australia only) } \\ \text { published as a journal article } & \end{array}$

Design: Retrospective cohor

(this study has multiple outcomes)
Population: Aborigina

Age: 20-84 years

Period: 2000-09
Data Source: Linked hospital and death records

Setting: Western Australian hospita cases

Other: 15-year clearance period

Sample size: 37,097 AF cases, 923 Aboriginal; 5,417 mortality events
In-hospital mortality following admission

with AF as principal diagnosis: Native

Americans vs Whites adjusted HR 0.7 ( $p=0.3$

NOS (adapted for cross sectional)

8/10 Unlinked data; short follow-up

1-year mortality: cross-over effect 30-day mortality: Demography-adjusted $H R=1.7$

NOS (cohort): 9/9 Hospitalised case only AF codes not validated No diagnostic tests and therapeutic data (hospital deaths only)

Fully adjusted HR $=0.81$ (NS) 1-yr mortality in 30-day survivors: Demography-adjusted $\mathrm{HR}=2.9$

Fully adjusted $\mathrm{HR}=1.6$ Comorbidities impact substantially on attenuation of effect 
Table 3 Studies of atrial fibrillation outcomes (Continued)

AF as an outcome

Title: Racelethnicity and the incidence of new-onset atrial fibrillation after isolated coronary artery bypass surgery

Nazeri (2010) [42] Journal article Country: US

Design: retrospective cohort

Cumulative incidence prior to discharge

of new-onset post-operative AF

NOS (cohort) 7/9 Descriptive study

only in relation to Native Americans

(crude percentages; no statistical inference) Very small number of Native Americans

Caucasians: $32.4 \%$ Native Americans: $18.8 \%$ insufficient for multivariate analysis

Pop: Native Americans

Data Source: Institutional research database

Period: $2000-2008$

Setting: Single tertiary hospital

Sample size: Total: 5823

Native American: 11 (0.2\%)

NOS Newcastle-Ottawa Scale, US United States, AF atrial fibrillation, HR hazard ratio 
provides data on all discharges from approximately 1000 hospitals, investigated in-hospital mortality of patients with a primary discharge diagnosis of AF [41]. Native Americans accounted for $0.75 \%$ of the sample of 425,470 hospitalisations. The odds ratio for in-hospital mortality following admissions of Native American versus White, adjusted for age, sex and comorbidities, was 0.732 (CI $0.227-2.358, p=0.30$ ). Limitations of the database precluded a person-based analysis that could track readmissions.

In the Western Australian study based on linked hospitalisation and mortality records [30], there was a cross-over of early survival, with 30-day adjusted mortality tending to be lower (not significant) in Aboriginal than non-Aboriginal patients in their first-ever AF admission. However, the adjusted hazard ratio for one-year mortality in Aboriginal versus non-Aboriginal 30-day survivors was 1.58. Comorbidities and a secondary diagnosis of AF, both more common in Aboriginal patients, were strong independent predictors of mortality. Comorbidities contributed substantially to the attenuation of effect in adjusted models.

\section{AF as a complication}

A single study from the USA investigated the influence of ethnicity on the likelihood of AF as a postoperative outcome of coronary artery bypass surgery (Table 3). In this single tertiary referral hospital study, Native Americans constituted only $0.2 \%$ of the total sample of 5823. In crude comparison, new-onset postoperative AF occurred in $18.8 \%$ of Native Americans (mean age 61 years) versus $32.4 \%$ of Causasians (mean age 65) [42].

\section{AF in clinical groups}

Although studies with data on the occurrence of AF in specific clinical groups accounted for the majority of publications identified, AF was not usually the primary research focus (Table 4). Most were conducted in hospital settings and provided crude prevalence data only.

\section{Frequency of atrial fibrillation in primary care consultations} Only a single Australian report provided data on the comparative frequency of AF among Indigenous versus non-Indigenous patients in primary care consultations. The Bettering the Evaluation and Care of Health (BEACH) survey provides written questionnaire data provided by a random sample of general practitioners (GPs) across Australia [40]. In the period 2006-7 to 2011-12, participating GPs reported managing AF during 38 'Indigenous' and 5548 'Other' consultations, reflecting an age-standardised Indigenous:non-Indigenous rate ratio of $1.3(p=\mathrm{NS})$. Authors of the report suggested that the Indigenous identity of patients had likely been underestimated, making interpretation of the finding problematic.

\section{Frequency of atrial fibrillation in hospital admissions}

Data on the frequency of AF-coded admissions among hospitalised Indigenous versus non-Indigenous patients were recently published in a large single-institution South Australian study that reported on 204,668 admissions (5,892 Indigenous [3.6\%]) to a tertiary referral centre during the decade 2000-2009 [29]. Indigenous subjects with AF were substantially younger on average than their non-Indigenous counterparts (55.4 years versus 74.5 years). Among admitted patients aged $<60$ years, the proportion of AF diagnosed was considerably higher among Indigenous patients ( $2.7 \%$ vs $1.7 \%, p<0.0001)$, while these proportions were reversed in patients $\geq 60$ years (4.61\% vs $9.26 \%, p<0.0001)$. Interpretation of these single institution data is difficult as no population denominator was provided. Furthermore, the (unlinked) data did not allow differentiation of initial and repeat admissions.

\section{Frequency of atrial fibrillation in specific diagnostic groups}

(a) Heart failure. Two cohort studies based on wholejurisdictional linked administrative data comparing heart failure (HF) in Indigenous and non-Indigenous adult subjects ( $\geq 20$ years) included AF frequency among the reported baseline characteristics. In a cohort study from Alberta Canada, Lyons et al. undertook a study of mortality outcomes among patients hospitalised with incident HF, based on linked inpatient, emergency department, ambulatory care and insurance registry datasets. They reported a crude baseline prevalence of AF as a comorbidity of $\mathrm{HF}$ in $18 \%$ in Aboriginal patients versus $34 \%$ in 'Whites' $(p<0.0001)$ [43]. Importantly, however, this comparison was confounded by age (baseline mean age [years]: Aboriginal 63; White 75). In a Western Australian cohort study investigating first HF hospitalisation in Aboriginal versus non-Aboriginal patients, baseline crude prevalence of AF was significantly lower among Aboriginal patients in both younger and older age strata (20-54 years: Aboriginal $17.2 \%$, nonAboriginal $26.6 \%$ [ $p<0.001]$; $55-84$ years: Aboriginal $24.6 \%$, non-Aboriginal $=44.9 \%[p<0.001])$ [44].

(b) Ischaemic heart disease. No recent studies were found that provided data on AF among Indigenous patients with ischaemic heart disease (IHD). A single descriptive study from NZ investigated the clinical characteristics of patients admitted with IHD to the Coronary Care Unit of a single non-urban hospital during the period 1971-1980 [45]. AF was detected in $39 \%$ of Māori and $6 \%$ of non-Māori cases in crude comparison. 
Table 4 Studies of frequency of atrial fibrillation in clinical groups

\begin{tabular}{|c|c|c|c|c|}
\hline $\begin{array}{l}\text { Author (Year) } \\
\text { Publication type }\end{array}$ & $\begin{array}{l}\text { Country } \\
\text { Indigenous population } \\
\text { Calendar period }\end{array}$ & Methods & Key findings on Indigenous AF & $\begin{array}{l}\text { Quality score (Newcastle-Ottawa } \\
\text { Scale applied only to Indigenous } \\
\text { AF data) }\end{array}$ \\
\hline
\end{tabular}

Comments

(a) Frequency of atrial fibrillation in primary care consultations

Title: Aboriginal and Torres Strait Islander Health Performance Framework 2012 - Detailed Analyses

Australian Institute of Health Country: Australia_ Design: Cross-sectional

and Welfare (2013) [40]

Report

Pop: Aboriginal

Period: 2006-07 to 2011-12

(b) Frequency of atrial fibrillation in hospital admissions

Title: Atrial fibrillation in Indigenous and non-Indigenous Australians: a cross-sectional study

Wong (2014) [29] Country: Australia

Conference

abstract later published as a

journal article
Design: Retrospective cross-sectional study

Data Source: BEACH (written questionnaire, random sample of GPs across Australia)

Setting: General practice attendances

Sample size: AF managed during

38 'Indigenous' and 5548 'Other'

GP attendances
Age-standardised rate (no. of encounters

NOS (adapted for cross-sectional): 5/10 per 1,000 in which AF managed):

Indigenous: 15.1 (Cl 5.7-24.4) Other:

11.5 (Cl 11.0-12.0) Rate ratio 1.3 (NS)

Rate difference 3.5 (NS)

Likely under-identification of Indigenous patients

ndigenous vs non-Indigenous frequency NOS (adapted for cross-sectional): 5/10

of AF adjusted for age, sex \& CVD Unclear definition of AF occurrence comorbidity (odds age, sex \& CVD (Cl $0.977-1.432 ; p=0.085$ )

(throughout series of $\geq 1$ potential admission

per patient) No 'lookback' to establish age at 1st AF admission Representativeness of population uncertain from single institution

Denominator for comparisons unclear

Pop: Indigenous Australians (IA)

Period: 2000-2009
Data Source: Administrative data

Setting: Single tertiary hospital (South Australia)
Crude age-stratified frequency of AF

Indigenous vs non-Indigenous: $<60$ yrs 2.57 vs $1.73 \% p<0.0001$ $\geq 60$ yrs 4.61 vs $9.26 \% p<0.0001$

Average age of patients with AF (years) Indigenous 55.4 (SD 13.2) vs Non-

Indigenous

$74.5($ SD 13.1) $p<0.001$ 
Table 4 Studies of frequency of atrial fibrillation in clinical groups (Continued)

Sample size: 204668 persons

admitted (5892 Indigenous [3.6\%])

14373 patients with AF diagnosis

(221 Indigenous)

(c) Frequency of atrial fibrillation in specific diagnostic groups

i. Heart failure

Title: Incidence of first heart failure hospitalisation and mortality in Aboriginal and non-Aboriginal patients in Western Australia, $2000-2009$

$\begin{array}{ll}\text { Teng (2014) [44] Journal } & \text { Country: Australia } \\ \text { article } & \text { Design: baseline descriptive } \\ & \text { (within cohort study) hospitalised } \\ & \text { HF patients }\end{array}$

\section{Pop: Aboriginal}

Period: 2000-2009

Data Source: Linked hospital and death records

Setting: Hospital

Sample size: 1013 Aboriginal and 16,366 non-Aboriginal hospitalised HF patients

Title: Mortality outcomes among status Aboriginals and Whites with Heart Failure

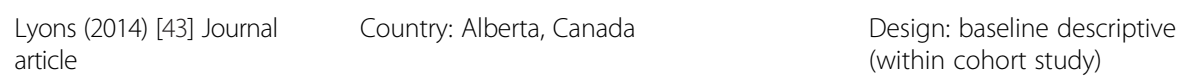

article (within cohort study)
Crude AF prevalence significantly higher

in non-Aboriginal patients: $20-55$ years non-Aboriginal patients: $20-55$ years 15

15-year clearance period to identify first HF

admission; codes validated; 5-year look back

for history of AF

Aboriginal $=17.2 \%$ Non-Aboriginal $=$

$26.6 \%$

$p<0.00155-84$ years

Aboriginal $=24.6 \%$ Non-Aboriginal $=$

$44.9 \%$

$p<0.001$

Crude prevalence of AF (as comorbidity): NOS (adapted for cross-sectional): 8/10

Aboriginals (18\%); Whites (34\%) Albertan Aboriginal population comprises

\%

dentification of Indigenous status in

study

based on registration-only First Nations

are

eligible, of whom $81 \%$ are registered.

Métis

classified as White in this study.
Pop: Aboriginal

Period: 2000-2008
Data Source: Health care administrative (HMD, ED, ambulatory care) databases linked to the insurance registry (with ethnicity recorded)

Setting: Hospital

Sample size: 42,288 whites,

1158 Aboriginals 
Table 4 Studies of frequency of atrial fibrillation in clinical groups (Continued)

ii. Ischaemic heart disease

Title: Ischaemic heart disease in New Zealand Māori and non-Māori: an age adjusted incidence in hospitalised patients over 10 years with emphasis on clinical features in the Māori

Dancaster (1982) [45] Country: NZ_ Design: Descriptive Journal article

Pop: Māori

\section{Period: 1971-1980}

iii. Renal failure

Title: Atrial fibrillation in haemodialysis patients: do the guidelines for anticoagulation apply?

To (2007) [48] Journal article Country: NZ

Pop: Māori

Period: 2003

Title: Trends in the incidence of atrial fibrillation in older patients initiating dialysis in the United States

Goldstein (2012) [47] Country: US Design: Cohort study

Journal article

follow-up unit

Design: Cohort study
AF detected in $39 \%$ of Māori versus $6 \%$

Data Source: Hospital records

\section{Design: baseline descriptive}

(within cohort study) Data Source:

Subjects identified from identified

from ANZ Dialysis and Transplant

Registry; Hospital records - 30 month

Setting: Single hospital haemodialysis

Sample size: 155 haemodialysis patients; 28 (18 \%) Māori, 51 (33\%)
Pacific Islander

\section{Crude}

Crude incidence rate: 148/1000 person-

Crude percentage AF: Caucasians $32.8 \%$ Māori $28.6 \%$ Pacific Islanders $19.6 \%$ Asians $16.7 \%$

NOS (adapted for cross-sectional): 6/10 Underpowered, therefore essentially descriptive study of AF prevalence

NOS (adapted for cross-sectional): 3/10 No statistical inference data given for AF proportions Old study - contemporary relevance uncertain

NOS (cohort): 9/9 Small sample size for Native Americans (1\%).

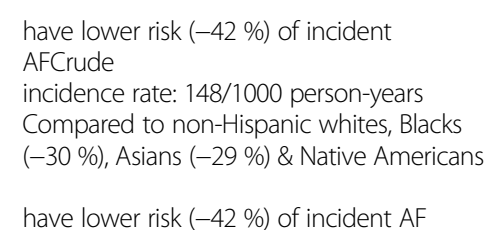

Pop: Native Americans Period: 1995-2007
Data Source: US Renal Data System

Setting: Population-based

(older Medicare beneficiaries) 
Table 4 Studies of frequency of atrial fibrillation in clinical groups (Continued)

Sample size: 258,605 (1 \% Native

Americans)

Title: The increasing prevalence of atrial fibrillation among hemodialysis patients

Winkelmayer (2011) [46] Country: US Design: series of cross-sectional Journal article

Pop: Native American surveys

Native American HD patients univariate RR for AF 0.38 (vs Causasian); adjusted RR $0.53(\mathrm{Cl} 0.50-0.57)$

Data Source: United States Renal Data System

Period: 1992-2006

Setting: maintenance hemodialysis pts—whole of USA

Sample size: $>10^{5}$ pts each year of study

iv. Stroke

Title: Prevalence of stroke and coexistent conditions: disparities between Indigenous and non-Indigenous Western Australians

Katzenellenbogen (2014) [49] Country: Australia Journal article

Pop: Aboriginal

Period: 2007-2011
Design: baseline descriptive

(within cohort study)

Data Source: Linked hospital and

death records

Setting: Hospital

Sample size: Average 13,59

patients per year ( $5 \%$ Aboriginal)

Title: Racial disparities among Native Hawaiians and Pacific Islanders with intracerebral hemorrhage

Nakagawa (2012) [50] Country: Hawaii, US Design: Cross-sectional

Journal article

\author{
Country: Hawaii, US
}

esign: Cross-sectional

Pop: Native Hawaiians \& Pacific Islander (NHPI)

Data Source: Clinical database

Period: 2004-2010

Setting: Hospital admissions from single tertiary hospital

Sample size: 562 ICH cases

Title: Disparities among Asians and native Hawailans and Pacific Islanders with ischemic stroke

Nakagawa (2013) [51] Country: Hawaii, USA Design: Cross-sectional

Journal article
Country: Hawaii, USA

Design: Cross-sectiona
AF more prevalent in Aboriginal than other stroke cases in all age groups $<70$ years. Crude AF rates were $20 \%$ less in Aboriginal patients due to differing age distributions.
NOS (adapted for cross-sectional): 7/10 (AF not focus of study) Long (20-year) look-back period to identify stroke and AF; AF codes not validated; no stroke type data
Crude prevalence of AF: No significant difference between whites \& NHPI$$
(10 \% \text { vs } 17 \%)
$$

AF prevalence: No significant difference between whites \& NHPI Crude prevalence

$15 \%$ vs $19 \%$ Adjusted OR 1.06 (0.64 1.75)
NOS (adapted for cross-sectional): 7/10

Single-centre (referral bias). Good clinica data. Limited analysis, given small sample size

NOS (adapted for cross-sectional): 8/10 Single-centre (referral bias). Good clinical data. 
Table 4 Studies of frequency of atrial fibrillation in clinical groups (Continued)

\begin{tabular}{ll}
\hline Pop: NHPI & Data Source: Clinical database \\
Period: 2004-2010 & Setting: Hospital admissions from \\
& single tertiary hospital \\
& Sample size: 1,921 ischaemic strokes
\end{tabular}

v. Rheumatic heart disease

Title: Percutaneous balloon mitral commissurotomy in Indigenous versus non-Indigenous Australians

$\begin{array}{ll}\text { McCann (2008) [52] Country: Australia } & \begin{array}{l}\text { Design: baseline descriptive } \\ \text { Journal article }\end{array} \\ \text { (within cohort study) }\end{array}$

Pop: Indigenous Australians

Period: 1990-2006

Title: A review of valve surgery for rheumatic heart disease in Australia

Russell (2014) [53] Country: Australia

Journal article

Pop: Aboriginal \& Torres Strait Islander

Data Source: National Cardiac

Surgery Database

Period: 2001-2012

\section{Setting: Hospitalised surgery patients}

Sample size: 1384 RHD (174

Indigenous)

compared with 15843 non-RHD

valvular surgery patients

vi. Other cardiac surgery

Title: Incidence, secular trends, and outcomes of cardiac surgery in Aboriginal peoples

$\begin{array}{ll}\begin{array}{l}\text { Sood (2013) [54] Journal } \\ \text { article }\end{array} & \begin{array}{l}\text { Design: baseline descriptive } \\ \text { (within cohort study) }\end{array}\end{array}$

Crude AF prevalence: non-significantly lower in Indigenous Australians (44\% vs $29 \%$ )

NOS (adapted for cross-sectional): 7/10 Only 36 (11\%) of Indigenous Australians. Age-adjusted survival was worse in Indigenous Australians.

Crude frequency of perioperative AF $(\%)$ Indigenous 33.3 Non-Indigenous 41.6 $(p=0.039)$ n.b., difference in mean age: Indigenous 37.4 years Non-Indigenous 65.1 year of crude frequencies of $\mathrm{AF}$ in the two ethnic categories is markedly confounded by age disparity

No significant difference in AF

prevalence

at baseline $(10.1 \%$ non-Aboriginal v $12.0 \%$ Aboriginal)
NOS (cohort): 9/9 Main aims were to compare Aboriginal vs non-Aborigin patients fo outcomes of cardiac surgery. Limited info on AF: crude baseline prevalence in a cohort with known selection bias (demonstrated disparity in selection for surgery) 
Table 4 Studies of frequency of atrial fibrillation in clinical groups (Continued)

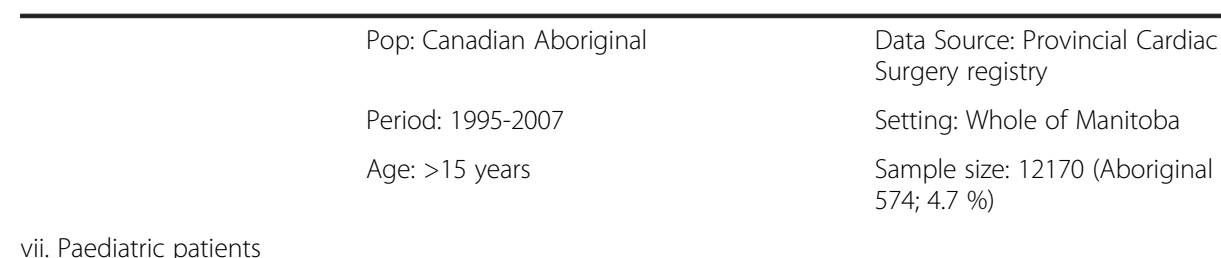

vii. Paediatric patients

Title: Excellent cardiac surgical outcomes in paediatric indigenous patients, but follow-up difficulties

Rohde (2010) [55] Country: Brisbane, AUS Design: Retrospective review

New atrial arrhythmia as post-surgical complication: $2.4 \%$
NOS (adapted for cross-sectional): $7 / 10$ Atrial arrhythymia was one endpoint (complication) of follow-up after cardiac surgery.

Pop: Indigenous Australians (paediatric)

Data Source: Cardiothoracic

database, chart review

Period: 2002-2009

Setting: Single tertiary hospital

Sample size: 112 cases (123

operations)

Title: Preoperative risk factors for long-term survival following cardiac surgery for rheumatic heart disease in the young

Remenyi (2012) [56]

Country: Auckland, NZ

Design: Retrospective cohort study

Pre-operative AF independently

predicted

mortality in multivariate analysis (HR 5.2

NOS: N/A (abstract) No Causasian $p<0.01$

comparison group

Pop: Māori \& PI

Data Source: Cardiothoracic

database,

chart review

Period: 1990-2006

Setting: Single tertiary hospital

Sample size: 212 cases

BEACH Bettering the Evaluation and Care of Health survey, GP general practitioner, NOS Newcastle-Ottawa Scale, AF atrial fibrillation, CVD cardiovascular disease, SD standard deviation, HF heart failure, HMD Hospital Morbidity Database, ED emergency department, NZ New Zealand, CCU coronary care unit, IHD ischaemic heart disease, ANZ Australia \& New Zealand, HD haemodialysis, RR relative risk, NHPI Native Hawaiian \& Pacific Islander, N/Anot applicable, HR hazard ratio, PI Pacific Islander 
(c) Renal failure. Two articles used the United States Renal Data System to report on the epidemiology of AF among dialysis patients with end-stage renal failure. In 2006, the odds ratio for prevalent AF among Native Americans $(\mathrm{n}=3332,1.7 \%$ of total) compared with Caucasian, after multivariate adjustment for age, gender, Medicaid coverage and comorbidities, was 0.55 (CI 0.480.63) [46]. Similarly, in longitudinal analysis of older patients ( $\geq 67$ years) initiating dialysis (total $n=258605$, Native Americans $~ 1 \%$ ), the incidence rate of new AF was $42 \%$ lower among Native American than Caucasian subjects (demographics- and comorbidity-adjusted hazard ratio 0.58 [0.53-0.63]) [47].

Data on baseline AF prevalence were reported from a single hospital haemodialysis unit in Auckland, NZ, in a cohort study investigating the risks and benefits of anticoagulation among haemodialysis patients with AF [48]. The crude AF prevalence was $29 \%$ in Māori $(n=8 / 28)$ versus $33 \%(19 / 58)$ in Caucasian subjects, with no data on age distribution according to ethnicity reported.

(d) Stroke. A whole-jurisdictional study of disparities in stroke prevalence between Indigenous and nonIndigenous Western Australians (2007-2011) reported the proportion of stroke patients with a history of AF determined by International Classification of Disease (ICD)-coded hospital diagnoses with 20-year lookback period [49]. The proportion of Indigenous stroke patients with an AF diagnosis was higher in all age-groups below 70 years, although the age-standardised proportions were similar in both ethnicity categories.

In paired cross-sectional studies from Hawaii, racial disparities were investigated among patients admitted with intracerebral haemorrhage (ICH) and those with ischaemic stroke. In patients with ICH ( $\mathrm{n}=562$ cases), the crude frequency of AF among Native Hawaiians categorised together with other Pacific Islanders (NHPI) was $10 \%$, compared with $12 \%$ in Asians and $17 \%$ in Whites $(p=\mathrm{NS})$ [50]. Notably, NHPI with ICH were significantly younger than whites (55 vs 66 years). In patients with ischaemic stroke ( $\mathrm{n}=1921$ cases), there was similarly no significant difference in the crude frequencies of $\mathrm{AF}$ at baseline between NHPI and other ethnic groups, but confounding by age was evident [51].

(e) Rheumatic heart disease. Two Australian studies provided data on AF among Indigenous subjects with rheumatic heart disease (RHD), but in neither of these was AF an outcome investigated. In a series of 327 patients (36 Indigenous) undergoing percutaneous balloon mitral commissurotomy, the measured difference in AF frequency between the two groups at baseline (44 \% non-Indigenous; $29 \%$ Indigenous) was not significant [52]. However, the average age of nonIndigenous subjects was substantially higher (52 versus 36 years). Similarly, a lower crude frequency of AF among Indigenous versus non-Indigenous RHD valvular surgery patients ( $33.3 \%$ versus $41.6 \% p=0.039$ ) reported from an Australia-wide cardiothoracic surgical database ( $\mathrm{n}=1384$ subjects) is difficult to interpret, given the marked age difference between groups [53].

(f) Other cardiac surgery. Based on a study using the Manitoba Provincial Cardiac Surgery registry, the crude frequency of AF between Aboriginal and non-Aboriginal aged over 15 years who had undergone cardiovascular surgery during 1995-2007 did not differ significantly (10.1\% versus $12.0 \% ; p=0.142$ ) [54]. This result did not account for the significant difference in mean age between the two ethnic groups.

(g) Paediatric AF. In a descriptive review of outcomes of cardiac surgery at a single tertiary institution in Australia, of all Indigenous paediatric patients (0-17 years) who had cardiac surgery performed in the period 2002-2009 (112 patients, 123 operations), 'new atrial arrhythmia' developed as a post-operative in-hospital complication in $2.4 \%$ of cases [55]. A retrospective single-institution study from Auckland, NZ investigating pre-operative determinants of long-term survival following cardiac surgery for RHD was reported in an abstract only. Māori and Pacific Islander children accounted for $98 \%$ of the cohort $(\mathrm{n}=212)$; pre-operative AF was an independent predictor of mortality (hazard ratio [HR] 5.2; $p<0.01)$ [56].

\section{Health service provision}

Only the study from Ontario on the Métis population provided data on health service provision for Indigenous AF, but numbers were small. The crude proportion of patients receiving outpatient echocardiography within 6 months of incident AF diagnosis was $52.9 \%$ in the the Métis ( $\mathrm{n}=56$ incident cases) compared with $42.1 \%$ in the general Ontarian population $(p=0.12)$ [31]. No meaningful data on receipt of evidence-based medications were identified for any of the Indigenous populations.

\section{Discussion \\ Principal findings}

Published data on AF in Indigenous populations in the affluent countries included in this review are scanty, fragmentary and of varying quality, with a minority subjected to peer-review. Aside from the potential for real differences in AF epidemiology among Indigenous populations between and within countries, study comparability is limited by differences in quality, design, analytical methods (including means of identifying Indigenous subjects and covariate adjustments), setting (community versus hospital) and calendar time frame. 
In consequence, the epidemiology of AF in these populations remains inadequately delineated, with no clear pattern emerging. However, both linked and unlinked administrative hospital data from Canada [28], Australia $[29,30]$, and NZ [39] suggest that hospitalised AF is more common at younger ages in Indigenous people, with higher first-ever AF hospitalisations in WA (notably under 65 years) and Ontario possibly reflecting disparities in population-based incidence. Concordant with these findings, small studies from Canada and NZ suggest higher AF prevalence among Métis and Māori respectively than the non-Indigenous comparator populations. In contrast, the significantly lower nationwide prevalence of AF among Native Americans than Whites reported in the US study of male military veterans, which incorporated both hospitalisation and ambulatory care data, suggest that higher AF occurrence in Indigenous populations may not apply in the US. Although no difference in short-term (30-day) post-admission mortality was found in the WA cohort, one-year mortality was higher among both WA Aboriginal patients and Ontarian Métis than among the respective comparator populations.

The major antecedents of AF traverse the 'epidemiological transition' [57], encompassing sequelae of infectious disease (with streptococcal infection underlying RHD) as well as non-communicable diseases (particularly hypertension and coronary atherothrombosis). As a generalisation, all of these occur in excess and at younger ages among Indigenous peoples, in both North America and Australasia [58-62]. Accordingly, the occurrence of AF would be expected to be correspondingly increased in these populations once age has been accounted for. However, the epidemiological pattern of these disparities is complex, varying among the specific disorders as well as within and between different countries, in magnitude and secular trends. Epidemiological surveillance of Indigenous populations for these underlying disorders remains suboptimal, partly because of inadequate Indigenous identifiers in routinely collected data, particularly in North America.

Unexpectedly, studies of AF frequency among ethnic minority groups such as African Americans, Hispanics and Europeans of African, Afro-Caribbean or IndoAsian ancestry suggest a 'racial paradox', i.e., that the condition is unexpectedly less common among these minority populations than Whites, despite the major risk factors generally being present in excess $[63,64]$. The US study of male veterans included in this review suggests that this phenomenon may extend to Native Americans. However, the findings of this study may not be generalisable to the whole US population, insofar as military recruitment is characterised by over-representation of lower socioeconomic strata and so may be disproportionately unrepresentative of the majority
'White' population, with under-participation of the most affluent. Recuitment also excludes persons with certain pre-existing health problems (such as congenital or rheumatic cardiac lesions predisposing to AF) and may represent a 'healthy worker' effect with those of poorer health not meeting enlistment criteria. Moreover, as outlined in a review of AF and race, ' $[\mathrm{u}]$ nder-ascertainment and differential mortality may partially contribute towards the apparent lower burden of AF [reported] in racial and ethnic minorities' [63]. No other published data elucidate the relative frequency of AF in the Native American population, despite the substantial research profile of Indigenous CVD in the US, notably that arising from the Strong Heart Study cohort, 'the largest epidemiologic study of American Indians ever undertaken' [65].

The available evidence suggests that the 'paradox' does not apply to Indigenous minorities in Canada, Australia and NZ and that AF frequency is increased among the Indigenous peoples of these countries, at least at younger ages. However, in interpreting hospitalisation data upon which the largest studies are based, it is important to recognise that frequency of first hospitalisation is not equivalent to incidence rate in a population. Hospitalisations are influenced by health-seeking behaviour and the quality of health care such that disparities between ethnic groups in access to care modify the likelihood of admission. Firstly, inadequate AF management in primary care-including tardy detection-may increase the likelihood of preventable hospitalisation and also skew the spectrum of hospitalised cases towards greater severity, due to poor control of the arrhythmia or associated conditions (such as heart failure) and complications (particularly stroke). Conversely, poor access to hospital care may diminish elective admissions for AF and associated morbidities. In order to establish the true incidence rate of the condition in a population, community-based, longitudinal cohort studies incorporating active surveillance are required. No study of this kind is available for the Indigenous peoples considered.

While a focus on inequities in social determinants and service provision is necessarily paramount in explaining the poorer health of Indigenous peoples, there is a possibility of inter-ethnic variation in genetic predisposition to specific disorders. In relation to AF, a lower prevalence among African Americans compared with Caucasians, despite the more common occurrence of major risk factors in the former, appears to be partly attributable to genetic factors $[64,66]$. The extent to which genetic variation modulates AF risk among diverse Indigenous peoples has not been investigated.

Disease outcome indices such as mortality and readmission rates are determined by both disease severity and quality of health service provision during and/or after hospitalisation. Rates for early mortality (30-day 
mortality among Western Australians following an AF admission and in-hospital mortality among US subjects admitted with AF) were not increased among Indigenous subjects, suggesting that they receive adequate in-hospital care. The data from Western Australia and Ontario reporting relatively high 1-year mortality following an AF hospitalisation could reflect greater severity of disease and/or poorer post-discharge management.

In view of the scanty data, publications were included in this review if they reported Indigenous versus nonIndigenous comparative AF frequency in specific clinical groups. The search results were dominated by these publications. Although several high quality cohort studies were identified, in most cases the principal hypotheses were unrelated to $\mathrm{AF}$, and the $\mathrm{AF}$ data were limited to baseline crude frequencies in patient subgroups, including comparisons between Indigenous and other ethnic groups. These data add little to the picture of AF epidemiology in Indigenous populations, except that they demonstrate that AF is characteristically a subsidiary consideration in clinical research, investigated in relation to comorbidities contributing to the clinical complexity of patients rather than examined in its own right. Such data are difficult to interpret, particularly because of the potential for substantial confounding by age and severity of underlying illness. An exception was a stroke prevalence study, showing higher proportions of AF comorbidity in Aboriginal Australians at all ages under 70 years [49]. Of note, age-standardisation did not adequately correct for age differences in that study.

Optimal clinical management of AF is predicated on access to high-quality health care, in relation to which Indigenous populations in general are demonstrably disadvantaged $[67,68]$. There is essentially no published evidence on equity of health services provision for $\mathrm{AF}$ in these populations although evidence from other cardiometabolic conditions suggests that they are likely to have higher rates of comorbidities that complicate their condition and management [69]. Besides the Ontario paper's crude comparison of receipt of echocardiography [31], our literature search identified a near absence of data on AF management in Indigenous people. In the broader population, barriers to optimal therapy of AF include underdiagnosis, underestimation of its prognostic severity, inadequate implementation of evidence-based therapeutic guidelines, limited access to care, and inadequate adherence to prescribed treatment [70]. These barriers are likely to be amplified among disadvantaged, marginalised groups such as Indigenous people [71]. AF is especially susceptible to under-diagnosis, given its propensity to be asymptomatic or to manifest with non-specific features, with a substantial proportion of strokes attributable to unrecognised AF [72]. Of particular concern are the many undiagnosed AF patients for whom long-term anticoagulant medication is necessary in order to prevent thromboembolic disease. Notably, since our literature search was performed, a large single-institution South Australian series of patients with known AF $(\mathrm{n}=19613$ patients; 308 Indigenous) documented that guideline-determined underuse and overuse of anticoagulant medications were both significantly more common (ORs 1.27 and 1.60 respectively) among Indigenous than non-Indigenous patients [73]. In general terms, the socio-economic and environmental factors predisposing Indigenous peoples to conditions associated with $\mathrm{AF}$ are also likely to compromise its clinical management [74].

\section{Strengths and limitations}

This scoping review contributes to a genre that brings together research on the health of Indigenous minorities living in affluent countries $[8,75-78]$. Its strengths include an exhaustive search of established databases, efforts to access the grey literature and appraisal of study quality to provide an overview of existing research into AF in Indigenous peoples of the selected countries. The principal limitation of the review was the need to frame its design as a scoping study without a focussed research question, based on anticipation of scanty published data. Furthermore, there are unavoidable trade-offs in the exhaustive approach to literature searching that extends beyond indexed academic databases. Although Google Scholar allows searching the full text of publications, thereby allowing recognition of data that may not be identified through subject headings keywords, titles and abstracts, this interface has less sophisticated functionality for systematic searching than traditional databases [79]. Furthermore, the 'grey' literature such as government websites is characterised by inconsistent quality by virtue of the absence of peer review, as well as poor searchability given the diversity of formats, the absence of controlled vocabulary indexing, and sheer volume [80]. The NOS used to appraise the quality of studies of non-randomised design is limited by subjectivity, as demonstrated by high inter-observer variation [81].

\section{Conclusions}

Accurate epidemiological data are a prerequisite to optimising the equity and efficiency of service provision for CVD among Indigenous people. AF is an eminently treatable condition. Timely detection of AF is necessary, firstly to maximise the chances of reversing to normal sinus rhythm if practicable, usually accompanied by addressing the underlying cause, and secondly to institute pharmacological management to reduce to the likelihood of potentially life-threatening complications. Relative underdetection and consequent skewing of hospital presentations are obstacles to quantifying the comparative frequency of $\mathrm{AF}$ in these populations satisfactorily 
$[30,63]$. Furthermore, the reduced life expectancies of Indigenous populations alter the age structure, requiring cautious interpretation of disparities in rates: conventional age standardisation and age-adjustments may not adequately control for age differences between Indigenous and non-Indigenous populations [49]. The small numbers of people belonging to Indigenous minorities also create challenges in making meaningful rate comparisons between groups within small age bands.

It is crucial that health systems in jurisdictions with Indigenous minorities incorporate data on Indigenous identity in routinely collected administrative health surveillance data from primary health care and hospitals [82, 83]. Optimally, sophisticated data linkage systems are needed to facilitate person-based (rather than merely event-based) surveillance measures, in order to identify incident cases, distinguish re-presentations/re-admissions and determine outcomes. The inclusion of AF in the conditions reported in government publications could begin to elucidate existing disparities and increase attention on the need for effective interventions. Additionally, there is an urgent need for sufficiently powered, community-based studies of AF epidemiology in diverse Indigenous populations that incorporate active case-finding and have a valid comparator population.

\section{Additional file}

Additional file 1: Table S1. Search terms 19 May 2014 (PubMed version) (DOCX $23 \mathrm{~kb}$ )

\begin{abstract}
Abbreviations
AF: Atrial fibrillation; ASRR: Age-standardised rate ratio; $\mathrm{BEACH}$ : Bettering the Evaluation and Care of Health; BMI: Body- mass index; Cl: Confidence interval; CVD: Cardiovascular disease; ED: Emergency department; GP: General practitioner; HF: Heart failure; HR: Hazard ratio; ICD: International Classification of Disease; ICH: Intracranial haemorrhage; IHD: Ischaemic heart disease; NHPI: Native Hawaiian and Pacific Islander; NOS: Newcastle-Ottawa Scale; NZ: New Zealand; RHD: Rheumatic heart disease; US: United States; WA: Western Australia.
\end{abstract}

\section{Competing interests}

The authors declare that they have no competing interests.

\section{Authors' contributions}

JMK conceived the study. JAW undertook the literature searches which were planned with the involvement of all authors. All authors participated in screening retrieved publications for relevance, and in extracting and tabulating data from included publications. JMK and JAW drafted the manuscript. All authors reviewed and revised the manuscript and have approved the final version.

\section{Acknowledgement}

This work was supported by the National Health and Medical Research Council of Australia (NHMRC) (Grant Number 1031057). JMK is funded by an NHMRC Early Career Fellowship (Number 037429). The Western Australian Centre for Rural Health receives funding from the Commonwealth Department of Health and Ageing.

\section{Author details}

${ }^{1}$ Western Australian Centre for Rural Health, The University of Western Australia (M706), 35 Stirling Highway, Crawley, Western Australia 6009,
Australia. ${ }^{2}$ School of Population Health, The University of Western Australia (M431), 35 Stirling Highway, Crawley, Western Australia 6009, Australia.

Received: 1 May 2015 Accepted: 3 August 2015

Published online: 13 August 2015

\section{References}

1. Donato $R$, Segal L. Does Australia have the appropriate health reform agenda to close the gap in Indigenous health? Aust Health Rev. 2013;37(2):232-8.

2. Statistics New Zealand. New Zealand Period Life Tables: 2010-12. Wellington: Statistics New Zealand; 2013.

3. Life expectancy: Gap in life expectancy projected to decrease between Aboriginal people and the total Canadian population. Accessed 6 Aug, 2015 [http://www.statcan.gc.ca/pub/89-645-x/2010001/c-g/c-g013-eng.htm]

4. Daniel M, Lekkas P, Cargo M. Environments and cardiometabolic diseases in aboriginal populations. Heart Lung Circ. 2010;19(5-6):306-15.

5. Vasilevska M, Ross SA, Gesink D, Fisman DN. Relative risk of cervical cancer in indigenous women in Australia, Canada, New Zealand, and the United States: a systematic review and meta-analysis. J Public Health Policy. 2012;33(2):148-64.

6. Cooke M, Mitrou F, Lawrence D, Guimond E, Beavon D. Indigenous wellbeing in four countries: an application of the UNDP'S human development index to indigenous peoples in Australia, Canada, New Zealand, and the United States. BMC Int Health Hum Rights. 2007;7:9.

7. Carson KV, Brinn MP, Labiszewski NA, Peters M, Chang AB, Veale A, et al. Interventions for tobacco use prevention in Indigenous youth. Cochrane Database Syst Rev. 2012;8:Cd009325.

8. Clifford AC, Doran CM, Tsey K. A systematic review of suicide prevention interventions targeting indigenous peoples in Australia, United States, Canada and New Zealand. BMC Public Health. 2013;13:463.

9. Chamberlain C, Yore D, Li H, Williams E, Oldenburg B, Oats J, et al. Diabetes in pregnancy among indigenous women in Australia, Canada, New Zealand, and the United States: a method for systematic review of studies with different designs. BMC Pregnancy Childbirth. 2011;11:104.

10. United Nations Department of Economic and Social Affairs. The State of the World's Indigenous Peoples (STA/ESA/328 Sales No. E.09.VI.13). New York: United Nations Publications; 2009.

11. Howard BV, Lee ET, Cowan LD, Devereux RB, Galloway JM, Go OT, et al. Rising tide of cardiovascular disease in American Indians. The Strong Heart Study. Circulation. 1999;99(18):2389-95.

12. Vos T, Barker B, Begg S, Stanley L, Lopez AD. Burden of disease and injury in Aboriginal and Torres Strait Islander Peoples: the Indigenous health gap. Int J Epidemiol. 2009;38(2):470-7.

13. Ball J, Carrington MJ, McMurray JJ, Stewart S. Atrial fibrillation: profile and burden of an evolving epidemic in the 21st century. Int J Cardiol. 2013;167(5):1807-24.

14. Chugh SS, Havmoeller R, Narayanan K, Singh D, Rienstra M, Benjamin EJ, et al. Worldwide epidemiology of atrial fibrillation: a Global Burden of Disease 2010 Study. Circulation. 2014;129(8):837-47.

15. Lip GY, Brechin CM, Lane DA. The global burden of atrial fibrillation and stroke: a systematic review of the epidemiology of atrial fibrillation in regions outside North America and Europe. Chest. 2012;142(6):1489-98.

16. Wilke T, Groth A, Mueller S, Pfannkuche M, Verheyen F, Linder R, et al. Incidence and prevalence of atrial fibrillation: an analysis based on 8.3 million patients. Europace. 2013;15(4):486-93.

17. Wasilewska M, Gosk-Bierska I. Thromboembolism associated with atrial fibrillation as a cause of limb and organ ischemia. Adv Clin Exp Med. 2013;22(6):865-73.

18. Ahmad Y, Lip GY, Lane DA. Recent developments in understanding epidemiology and risk determinants of atrial fibrillation as a cause of stroke. Can J Cardiol. 2013;29(7 Suppl):S4-13.

19. Stroke Risk in Atrial Fibrillation Working Group. Independent predictors of stroke in patients with atrial fibrillation: a systematic review. Neurology. 2007;69(6):546-54.

20. Task Force for the Management of Atrial Fibrillation (European Society of Cardiology). Guidelines for the management of atrial fibrillation. Eur Heart J. 2010;31(19):2369-429.

21. Andersson T, Magnuson A, Bryngelsson IL, Frobert O, Henriksson KM, Edvardsson N, et al. All-cause mortality in 272,186 patients hospitalized with 
incident atrial fibrillation 1995-2008: a Swedish nationwide long-term casecontrol study. Eur Heart J. 2013;34(14):1061-7.

22. Leong DP, Eikelboom JW, Healey JS, Connolly SJ. Atrial fibrillation is associated with increased mortality: causation or association? Eur Heart J. 2013;34(14):1027-30.

23. Brown A, Walsh W, Lea T, Tonkin A. What becomes of the broken hearted? Coronary heart disease as a paradigm of cardiovascular disease and poor health among Indigenous australians. Heart Lung Circ. 2005;14(3):158-62

24. Dang $D$, Patel R, Haywood LJ. Atrial fibrillation in a multiethnic inpatient population of a large public hospital. J Natl Med Assoc. 2004;96(11):1438-44.

25. The Newcastle-Ottawa Scale (NOS) for assessing the quality of nonrandomised studies in meta-analyses. Accessed 6 Aug, 2015 [http:// www.ohri.ca/programs/dlinical_epidemiology/oxford.htm]

26. Wong C, Cheng Y, Lau D, Leong D, Brooks A, Shipp N, et al. Atrial Fibrillation in Indigenous Aboriginal Australians. Heart Lung Circ 2010;19:S255.

27. Katzenellenbogen JM, Teng TH, Lopez D, Sanfilippo F, Knuiman M, Hobbs M, et al. Abstract PM265: The epidemiological profile of first-ever hospitalisations for atrial fibrillation in Aboriginal and non-Aboriginal Western Australians, 2000-2009. Global Heart. 2014; 6(15):e115.

28. Atzema CL, Kapral M, Klein-Geltink J, Asllani E. Cardiovascular Disease in the Métis Nation of Ontario: Technical Report. Toronto: Métis Nation of Ontario/ Institute for Clinical Evaluative Sciences; 2012.

29. Wong CX, Brooks AG, Cheng YH, Lau DH, Rangnekar G, Roberts-Thomson KC, et al. Atrial fibrillation in Indigenous and non-Indigenous Australians: a crosssectional study. BMJ Open. 2014;4(10), e006242.

30. Katzenellenbogen JM, Teng TH, Lopez D, Hung J, Knuiman MW, Sanfilippo FM et al. Initial hospitalisation for atrial fibrillation in Aboriginal and non-Aboriginal populations in Western Australia. Heart. 2015;101(9):712-9.

31. Atzema CL, Khan S, Lu H, Allard YE, Russell SJ, Gravelle MR, et al. Cardiovascular Disease Rates, Outcomes, and Quality of Care in Ontario Métis: A Population-Based Cohort Study. PLoS ONE. 2015;10(3), e0121779.

32. Zacks ES, Okin PM, Min J, Roman MJ, Lee ET, Howard BV, et al. Abstract 3203: Association of Markers of Inflammation with New-Onset Atrial Fibrillation in a Population-Based Sample: The Strong Heart Study. Circulation. 2006;114(II):678

33. Zacks ES, Okin PM, Min J, Roman MJ, Lee ET, Howard BV, et al. Abstract 2591: Association of Left Ventricular Mass and Ejection Fraction with New-Onset Atrial Fibrillation in a Population-Based Sample: The Strong Heart Study. Circulation. 2006;114(II):536.

34. Borzecki AM, Bridgers DK, Liebschutz JM, Kader B, Kazis LE, Berlowitz DR. Racial differences in the prevalence of atrial fibrillation among males. J Natl Med Assoc. 2008;100(2):237-45.

35. Brown A, Carrington MJ, McGrady M, Lee G, Zeitz C, Krum H, et al. Cardiometabolic risk and disease in Indigenous Australians: the Heart of the Heart Study. Int J Cardiol. 2014;171(3):377-83.

36. McGrady M, Krum H, Carrington MJ, Stewart S, Zeitz C, Lee GA, et al. Heart failure, ventricular dysfunction and risk factor prevalence in Australian Aboriginal peoples: the Heart of the Heart Study. Heart. 2012;98(21):1562-7.

37. Martin A, Doughty RN, Chieng N, Faatoese A, Gamble GD, Poppe K, et al. Twelve Lead Electrocardiographic Findings Among Maori and non-Maori at Risk of Cardiovascular Disease in NZ. Heart Lung Circ. 2013;22:569.

38. Teh RO, Martin A, Kerse N, Dyall L, Doughty RN. The Burden of Atrial Fibrillation in Octogenarians. Heart Lung Circ. 2013;22:580.

39. New Zealand Guidelines Group. The Management of People with Atrial Fibrillation and Flutter: Evidence-based Best Practice Guideline. Wellington: NZGG; 2005.

40. Australian Institute of Health and Welfare. Aboriginal and Torres Strait Islander Health Performance Framework 2012: detailed analyses. Cat. no. IHW 94. Canberra: AlHW; 2013.

41. Turagam MK, Velagapudi P, Visotcky A, Szabo A, Kocheril AG. African Americans have the highest risk of in-hospital mortality with atrial fibrillation related hospitalizations among all racial/ethnic groups: A nationwide analysis. Int J Cardiol. 2012;158(1):165-6.

42. Nazeri A, Razavi M, Elayda MA, Lee W, Massumi A, Wilson JM. Race/ethnicity and the incidence of new-onset atrial fibrillation after isolated coronary artery bypass surgery. Heart Rhythm. 2010;7(10):1458-63.

43. Lyons KJ, Ezekowitz JA, Liu W, McAlister FA, Kaul P. Mortality outcomes among status Aboriginals and Whites with Heart Failure. Can J Cardiol. 2014;30(6):619-26
44. Teng TH, Katzenellenbogen JM, Thompson SC, Sanfilippo FM, Knuiman M, Geelhoed $\mathrm{E}$, et al. Incidence of first heart failure hospitalisation and mortality in Aboriginal and non-Aboriginal patients in Western Australia, 2000-2009. Int J Cardiol. 2014:173(1):110-7.

45. Dancaster CP, Tait RC. Ischaemic heart disease in New Zealand Maori and non-Maori: an age adjusted incidence in hospitalised patients over 10 years with emphasis on clinical features in the Maori. Aust N Z J Med. 1982;12(4):267-70

46. Winkelmayer WC, Patrick AR, Liu J, Brookhart MA, Setoguchi S. The increasing prevalence of atrial fibrillation among hemodialysis patients. J Am Soc Nephrol. 2011;22(2):349-57.

47. Goldstein BA, Arce CM, Hlatky MA, Turakhia M, Setoguchi S, Winkelmayer WC. Trends in the incidence of atrial fibrillation in older patients initiating dialysis in the United States. Circulation. 2012;126(19):2293-301.

48. To AC, Yehia M, Collins JF. Atrial fibrillation in haemodialysis patients: do the guidelines for anticoagulation apply? Nephrology (Carlton). 2007;12(5):441-7.

49. Katzenellenbogen JM, Knuiman MW, Sanfilippo FM, Hobbs MS, Thompson SC. Prevalence of stroke and coexistent conditions: disparities between indigenous and nonindigenous Western Australians. Int J Stroke. 2014;9 Suppl A100:61-8.

50. Nakagawa K, Koenig MA, Seto TB, Asai SM, Chang CW. Racial disparities among Native Hawaiians and Pacific Islanders with intracerebral hemorrhage. Neurology. 2012;79(7):675-80.

51. Nakagawa K, Koenig MA, Asai SM, Chang CW, Seto TB. Disparities among Asians and native Hawaiians and Pacific islanders with ischemic stroke. Neurology. 2013;80(9):839-43.

52. McCann AB, Walters DL, Aroney CN. Percutaneous balloon mitral commissurotomy in Indigenous versus non-Indigenous Australians. Heart Lung Circ. 2008;17(3):200-5.

53. Russell EA, Tran L, Baker RA, Bennetts JS, Brown A, Reid CM, et al. A review of valve surgery for rheumatic heart disease in Australia. BMC Cardiovasc Disord. 2014;14:134.

54. Sood MM, Tangri N, Komenda P, Rigatto C, Khojah S, Hiebert B, et al. Incidence, secular trends, and outcomes of cardiac surgery in Aboriginal peoples. Can J Cardiol. 2013;29(12):1629-36.

55. Rohde SL, Matebele M, Pohlner P, Radford D, Wall D, Fraser JF. Excellent cardiac surgical outcomes in paediatric indigenous patients, but follow-up difficulties. Heart Lung Circ. 2010;19(9):517-22.

56. Remenyi B, Webb R, Finucane K, Sidhu K, Gentles T, Wilson N. Preoperative risk factors for long-term survival following cardiac surgery for rheumatic heart disease in the young. Circulation. 2012;125(19), e723.

57. Yusuf S, Reddy S, Ounpuu S, Anand S. Global burden of cardiovascular diseases: part I: general considerations, the epidemiologic transition, risk factors, and impact of urbanization. Circulation. 2001;104(22):2746-53.

58. Anand SS, Yusuf $S$, Jacobs R, Davis AD, Yi Q, Gerstein $H$, et al. Risk factors, atherosclerosis, and cardiovascular disease among Aboriginal people in Canada: the Study of Health Assessment and Risk Evaluation in Aboriginal Peoples (SHARE-AP). Lancet. 2001;358(9288):1147-53.

59. Brown A, Brieger D, Tonkin A, White H, Walsh W, Riddell T, et al. Coronary disease in indigenous populations: summary from the CSANZ indigenous Cardiovascular Health Conference. Heart Lung Circ. 2010;19(5-6):299-305.

60. Go AS, Mozaffarian D, Roger VL, Benjamin EJ, Berry JD, Blaha MJ, et al. Heart disease and stroke statistics-2014 update: a report from the American Heart Association. Circulation. 2014;129(3):e28-292.

61. Steer AC, Carapetis JR. Acute rheumatic fever and rheumatic heart disease in indigenous populations. Pediatr Clin North Am. 2009;56(6):1401-19.

62. Tobias M, Yeh LC, Wright C, Riddell T, Chan WC, Jackson R, et al. The burden of coronary heart disease in Maori: population-based estimates for 2000-02. Aust N Z J Public Health. 2009:33(4):384-7.

63. Amponsah MK, Benjamin EJ, Magnani JW: Atrial Fibrillation and Race - A Contemporary Review. Curr Cardiovasc Risk Rep. 2013;7(5):336-345.

64. Gbadebo TD, Okafor H, Darbar D. Differential impact of race and risk factors on incidence of atrial fibrillation. Am Heart J. 2011;162(1):31-7.

65. The Strong Heart Study. Accessed 6 Aug, 2015 [http://strongheart.ouhsc.edu/]

66. Marcus GM, Alonso A, Peralta CA, Lettre G, Vittinghoff E, Lubitz SA, et al. European ancestry as a risk factor for atrial fibrillation in African Americans. Circulation. 2010:122(20):2009-15.

67. Graham GN, Guendelman M, Leong BS, Hogan S, Dennison A. Impact of heart disease and quality of care on minority populations in the United States. J Natl Med Assoc. 2006:98(10):1579-86. 
68. Hayman N. Strategies to improve indigenous access for urban and regional populations to health services. Heart Lung Circ. 2010;19(5-6):367-71.

69. Lopez D, Katzenellenbogen JM, Sanfilippo FM, Woods JA, Hobbs MS, Knuiman MW, et al. Disparities experienced by Aboriginal compared to non-Aboriginal metropolitan Western Australians in receiving coronary angiography following acute ischaemic heart disease: the impact of age and comorbidities. Int J Equity Health. 2014;13(1):93.

70. Prystowsky EN, Camm J, Lip GY, Allessie M, Bergmann JF, Breithardt G, et al. The impact of new and emerging clinical data on treatment strategies for atrial fibrillation. J Cardiovasc Electrophysiol. 2010;21(8):946-58.

71. Brown A. Acute Coronary Syndromes in Indigenous Australians: Opportunities for Improving Outcomes Across the Continuum of Care. Heart Lung Circ. 2010;19(5-6):325-36.

72. Lowres N, Neubeck L, Redfern J, Freedman SB. Screening to identify unknown atrial fibrillation. A systematic review. Thromb Haemost. 2013;110(2):213-22.

73. Wong CX, Lee SW, Gan SW, Mahajan R, Rangnekar G, Pathak RK, et al. Underuse and overuse of anticoagulation for atrial fibrillation: A study in Indigenous and non-Indigenous Australians. Int J Cardiol. 2015;191:20-4.

74. Brown AD, Morrissey MJ, Sherwood JM. Uncovering the determinants of cardiovascular disease among Indigenous people. Ethn Health. 2006;11(2):191-210.

75. Parker EJ, Jamieson LM, Broughton J, Albino J, Lawrence HP, RobertsThomson K. The oral health of Indigenous children: a review of four nations. J Paediatr Child Health. 2010;46(9):483-6.

76. Glover M, Kira A, Johnston V, Walker N, Thomas D, Chang AB, et al. A systematic review of barriers and facilitators to participation in randomized controlled trials by Indigenous people from New Zealand, Australia, Canada and the United States. Glob Health Promot. 2015;22(1):21-31.

77. DiGiacomo M, Davidson PM, Abbott PA, Davison J, Moore L, Thompson SC. Smoking cessation in indigenous populations of Australia, New Zealand, Canada, and the United States: elements of effective interventions. Int J Environ Res Public Health. 2011;8(2):388-410.

78. Bowen A, Duncan V, Peacock S, Bowen R, Schwartz L, Campbell D, et al. Mood and anxiety problems in perinatal Indigenous women in Australia, New Zealand, Canada, and the United States: a critical review of the literature. Transcult Psychiatry. 2014;51(1):93-111.

79. Boeker M, Vach W, Motschall E. Google Scholar as replacement for systematic literature searches: good relative recall and precision are not enough. BMC Med Res Methodol. 2013;13:131.

80. Turner AM, Liddy ED, Bradley J, Wheatley JA. Modeling public health interventions for improved access to the gray literature. J Med Libr Assoc. 2005;93(4):487-94.

81. Hartling L, Milne A, Hamm MP, Vandermeer B, Ansari M, Tsertsvadze A, et al. Testing the Newcastle Ottawa Scale showed low reliability between individual reviewers. J Clin Epidemiol. 2013;66(9):982-93.

82. Randall DA, Lujic S, Leyland AH, Jorm LR. Statistical methods to enhance reporting of Aboriginal Australians in routine hospital records using data linkage affect estimates of health disparities. Aust N Z J Public Health. 2013;37(5):442-9.

83. Thompson SC, Woods JA, Katzenellenbogen JM. The quality of indigenous identification in administrative health data in Australia: insights from studies using data linkage. BMC Med Inform Decis Mak. 2012;12:133.

\section{Submit your next manuscript to BioMed Central and take full advantage of:}

- Convenient online submission

- Thorough peer review

- No space constraints or color figure charges

- Immediate publication on acceptance

- Inclusion in PubMed, CAS, Scopus and Google Scholar

- Research which is freely available for redistribution

Submit your manuscript at www.biomedcentral.com/submit 